\title{
RELIGION AND CONFLICTS OF VALUE IN CONTEMPORARY BRAZILIAN SOCIETY
}

\author{
Luiz Fernando Dias Duarte ${ }^{1}$
}

The relatively new area of studies of an "Anthropology of Christianity" - i. e., studies about the interaction between tribal cultures and Christian religion - has been immensely dynamic and promising.

Although the spread of Christianity has always occurred with both the conversion of urban and metropolitan worlds (as it happened with the major centers of the Roman Empire) and the conversion of local populations, which thus were distanced from their traditional symbolic systems, and this last process enormously accelerated with the great mercantile European voyages and colonial expansion, it was only a few decades ago that the systematic observation and ethnographic analysis of such massive conversions became a focus, with the increase of anthropological investment across continents and cultural areas.

The main characteristic of this new configuration is that of being connected with the ethnography of ongoing processes (or that are temporally very recent), in which the dynamics of the cosmological and sociological transformation involved in the conversion to Christianity seems more clear and open to a more precise observation and interpretation, at least in relation to the long and influential tradition of studies of religious syncretism, but with a long historical implantation, as in the case of the Andean world or of African-American religiosity. In the several cases in which processes of recent Christianization mingled with colonial dynamics, especially in Africa and

Oceania, this condition was often not included in the framework of analysis in the name of ethnological purity. These cases could also be analyzed mainly from the political point of view, in detriment of the cosmological and moral dimension. The same political bias indelibly marked studies of the messianic movements and cargo cults emerging in all colonial fronts; although it is also possible to consider that their usually transitory character and potential for confrontation with the powers that be hampered a considered observation and an understanding of the more subtle mechanisms with which they were involved.

1 Professor of the PPGAS/Museu Nacional, UFRJ. Contact: lfdduarte@uol.com.br 
Joel Robbins has been one of the most prominent names in this front of studies, with his rich ethnography of the New Guinea Urapmin's transition to Christianity and a series of works scrutinizing the heuristic implications of such processes. He has contributed to the re-discussion of several important issues, such as the opposition between continuity and discontinuity in the interpretation of the changes involved in the conversion to Christianity (Robbins, 2003 e 2007).

In this study, Robbins goes back to his Melanesian ethnographic treasure to propose some critical twists in the comprehension of the confrontation between traditional cosmology and Christian novelty - with the possibilities of there being contributions to the debate on the religious dynamics of national states such as Brazil. The crux is, as he announces, the emphasis on "values" and their empirical multiplicity in each society, and on the revealing character of the "rituals", for the comprehension of how values are articulated specially in many sided and potentially conflicting situations.

Emphasizing the dimension of values is a sign of the influence of L. Dumont's thought on Robbins, bringing back the vitality of Dumontian ethnology, which is partially obscured in Brazil by the other side of his theory: the contributions to the study of complex societies, - such as the Brazilian - characterized by the weight of the individualistic ideology, which he helped to understand as a precise historical phenomenon. When I started to make personal contact with Dumont in the mid-1980s, as the organization of Homo aequalis II was already practically articulated, he was focused on the seminars of his Melanesist colleague Daniel de Coppet (and also, by that time, of his disciple André Iteanu). He was as curious as ever about those cultural contexts that could not be explained by the opposition between holism and individualism that he had proposed in the context of comparison between India and the West (Dumont 2000:216).

When one is aware of the preeminence that Melanesist studies hold today in anthropological thought, Robbins' use of the heuristic power of Dumontian thought - a pioneer in the relativization of Western representations involved in the structure of anthropological categorization - is even more strategic. The proposal of a Melanesian "relationalism", based on the Urapmin ethnography, surely enriches that line of thought. It somehow eases, at least in the terminological level, the difficulties I encountered when proposing to characterize as holistic the otherness of Brazilian urban popular culture in relation to the hegemonic individualism found in the learned culture of the middle and upper classes (Duarte, 1986; Salem, 2006).

Inspired by the Dumontian theme of the tense, contradictory and creative relations between great ideological configurations, in this article Robbins develops the difference between "pluralism" 
and "multiplicity", on the one hand, and the difference between "religious pluralism" and "pluralism of values" on the other. As he opportunely highlights, the current notion of pluralism is intimately connected with the values of freedom and equality and thus constitutes itself a characteristic element of the modern individualistic configuration. It refers to a wide range of actual problems, but does not have the empirical amplitude that the notion of "multiplicity" has, able as this is to describe all cases of concomitant diversity, probably universal as they are, without the libertarian assumption of the former.

The current notion of "religion", both in the common and in the social science meaning, is also inseparable from Western ideological configuration, with its dominant individualistic and rationalistic strain. Thus, religion is considered to be a specific structure of practices and representations, of beliefs and rituals, organized by a more or less centered and bureaucratized institution - as in the ideal type of the Weberian "church". The "sect", within this context, is a slightly more relaxed and charismatic version of the same discrete model of social organization. A religion, beyond this institutional nature, primarily based on the specific historical experience of modern Christianity, has a segmented nature in relation to the social formation and ideological configuration in which it participates: a religion is no longer the cosmic whole, but only a particular expression of reality, different, for example, from politics, health or agriculture. Here again the embeddedness in modern Western culture is revealed, with its characteristic segmentation of areas, such as politics and economy - these cornerstones of modernity (Dumont, 1977; reporting to the original analysis by K. Polanyi).

A third element can be added here: the rationalist or intellectualist bias contained in the notion of religion as a system of beliefs, ideas, representations, organized in written canons, as in the case of the "religions of the book", in detriment of their actual manifestations - practical and pragmatic, ordinary or ritual - or of the multifaceted experiments of social exchange enacted under the aegis of some compelling moral principles (Pouillon, 1979).

The inconvenience of using a category endowed with such attributes to describe most of "religious" human experience has long been perceived, especially in ethnological studies of smallscale societies, adopting phrases such as "cosmology" or, more recently, "ontology", as more adequate in accounting for the totality, the ubiquity and the performativity of those comprehensive configurations of values. Therefore, it is not surprising that the ethnologist Robbins suggests we privilege the issue of "values" and, more than that, that they should be observed in "rituals", this preeminent arena of their enactment and assertion. 
However, many cosmologies tend to formally crystallize into religions, even outside of Western influence, but with much more strength in the many situations where the Christian model, in the form of church or sect, imposes itself as the dominant standard or inevitable interlocutor. This is mostly the prevailing situation in contemporary national societies, bearers of the great Western institutional model. It is only in peculiar situations of distance from national powers, as in the Urapmin society, that one can experience the influence of Christian cosmology without having to adopt the Christian "religion", except nominally. The complex gradient of situations of contact can lead, of course, to a gradual institutionalization of these holistic experiments, as occurs on all the fringes of the modern globalized world (as in the case of the Brazilian Amazon Koripako analyzed by Xavier, 2013, e. g.).

On the other hand, one should not forget that, even within national societies, areas of more fluid and performative religiosity can spread, such as those growing under the comprehensive title of "new age", or those that always transit between different religions, without institutional compromises or ideological adherence in search of stability and coherence.

When dealing with contemporary Brazilian national society, the most notable trait must inevitably be the ubiquity of the legitimacy of the Christian model in its most general sense, by virtue of quite evident historical reasons. It is well-known how much African-Brazilian religiosity has drawn from this ideological and institutionally omnipresent reference, but the same could be said of subsequent religions not marked by the political imprint of slavery. Both Kardecist spiritism and the recent institutional developments associated with ayahuasca carry traits of an indelible Christianity.

Brazilian Christianity has been sufficiently vast and permeating to allow, on another level, the proliferation of local variations, with quite different ideological, moral and ritual emphases, in spite of attempts of centralization and standardization undertaken from Rome. The sociology of religion in Brazil has looked into all the intricacies of this complex configuration, into the niches of "popular Catholicism", messianic movements and "African-Brazilian cults", making use or not of the analytical category of syncretism.

In general, it was not at all evident that "conversions" should be examined, although they existed in different directions, especially in the strict sense of the passage from Catholicism to historical Protestant religions, which affected only localized minorities. Such a categorical notion as "conversion" was not used to describe those discrete and stealthy movements and transits (or "passages", as proposed by Birman, 1996), which characterized the approximation of Catholics to 
Spiritist or Umbanda cults, for example, religiosities that were not demanding in terms of ecclesiastical affiliation.

The unexpectedly quick development of the adherence to Pentecostal denominations, from the 1970s on, publicly and massively brought to the fore this issue, as has been widely discussed in the last decades. The conversion in such cases is, nevertheless, essentially intra-Christian, even though committed to a serious rupture with the previous world. However, as the connection with the Catholic Church had already been nominal for quite a while for most believers - the so-called "non practicing Catholics" - both in the working classes and other social classes, what was left behind with the conversion to Pentecostalism was more a life style than a true cosmological or ideological commitment. This point has been amply confirmed by analysis, both in relation to specific denominations, or to any rhythms of transit or passage.

The issue that confronts us in Robbins text is thus very peculiar, revealing the effectiveness of this new "point of view" that he explicitly proposes. What weight and meaning do "values" and "rituals" have in such widespread and intense movements occurring at all levels of our society?

The first point seems to be more critical, even if one can discuss the meanings of the category "values." I myself, a few years ago, presented the hypothesis that the passages among the different Brazilian Christian religions could not be understood, especially among popular segments, as "religious options" in the strict sense. I proposed that, the most critical, structuring values involved in such decisions were disseminated in Brazilian culture in general, following certain dynamics, now widely extra religious -even secular - one could say.

I drew attention to the fact that the two values that seemed most prominent, most structural there, presented contradictions in some of their aspects, or in the possibility of their coexistence; and what led to this or that religious choice was the desirability of producing a regimen of increased coherence (or convenience), especially in challenging situations, crisis or affliction involving what I called "private ethos" (Duarte, 2005).

I also took into account that, given the characteristics of modern liberal public policy, the traditional relationship between an encompassing religious cosmology and encompassed secular speculations was reversed: the secular principles take the form of an encompassing ideology, while the former comprehensive cosmology is broken into fragments of religious "speculation". The "religious" messages, when presented in the modern world as different in their pastoral contents, and having to be explicit concerning this difference, tend also to be perceived as distributed in the form of a "market", theoretically available to personal choice; while the modern ideology, because 
it is vastly dominant, fluid and uncontroversial (except in the more technical dimensions of its formulas, inaccessible to lay consumers) can be presented to the public view as a fairly stable and undisputed continent (Duarte et al., 2006).

A corollary of this understanding is that many important "conversions" take place within the secular area, only occasionally connected with the religious world. I think about the individualizing passages that occur because of the continued and systematic access to higher culture, through education - knowing what this implies in terms of distance in the Brazilian social world. But also, I think about the ones deriving from the equally continued and systematic experience of some political militancy, through unions and partisanship. At some point I discussed these processes, distinguishing them from the more typical "social mobility", the one imposed by the differential economic accumulation and exposure to upper social strata (Duarte \& Gomes, 2008). The male Pentecostal pastoral experience is an individualizing process that often takes on the intensity of a secular conversion within a religious conversion.

The substantive analysis of the values I refer to, "subjectivism" and "naturalism," should not deserve to be resumed in this text, but for the fact that they are closely related to the themes of "individualism" and "relatedness", which are so essential for Robbins. The subjectivism, as I described it elsewhere, is nothing but a manifestation of the increasing capillarization of elements of the individualistic ideology, even in the popular world, so slightly affected by the formal dissemination of individualism through education and experience of the great liberal civic issues. Naturalism seems less obvious in its characterization, at least as a trace of the culture of the popular classes, distanced from the deeper sources of legitimacy of science and philosophical realism. For me, these values appeared to be like two branches of the same affiliation to modernity - the former through "qualitative individualism", romantic autonomy and uniqueness, the latter in the form of rationalism, "quantitative individualism", and universalistic Enlightenment. I recognized the latent, underlying presence of the relatedness, this "pre-eminence of reference to the value of "family", describable in terms which are similar to those of Robbins, as a counterpoint to the profound forces of modernizing transformation.

Reviewing my analysis now, in the light of Robbins' proposal, I realize that, besides the contradictions and confrontations that I described between subjectivism and naturalism in the everyday life of these segments of Brazilian society (as in the case of abortion, for example), perhaps one may consider the possibility that naturalism is often at the service of relationalism - a quite paradoxical situation if one takes into consideration the historical sources of both ideological 
trends. The material I presented, coming from different sources (Duarte et al., 2009a), described how arguments on the strength and legitimacy of "nature" and "life" - although they often referred to the technical resources of biomedicine - ended up working towards the recognition of kinship ties, the fundamental field of relatedness. Consanguinity, which is so intrinsic to Western cosmology, assumed in this case, as always, the role of a double axis between a physical naturalness and an emotional, relational one. Naara Luna's data on artificial reproduction were especially loquacious in this sense.

There is a clear equivalent to all these situations in Robbins' descriptions of the confrontations and contradictions between orders of value for the Urapmin. What is different is the existence in Brazil of a secular, intra-mundane sphere, considered to be alien to religion and governed by a universalistic rationality. Deriving as it does, however, from Christian cosmology, through complex and paradoxical paths, it operates as a worldview that is as "religious" as any other, if we understand as such the encompassing cognitive and moral ordering of a meaningful world, a worldview. What the so-called "religions" do today is to carve cosmological possibilities out of this unholy canopy and add to them a message and a specific experience style, expecting more or less stabilized attendances and adherences. The basic structuring values are there, articulated in the most varied ways, inspiring multiple ethical solutions. It is therefore quite appropriate to recognize that in Brazilian society the multiplicity of values proposed by Robbins occupies the place of a religious pluralism that indeed exists, but only as an ideal of some of the segments of the learned elite.

It is imperative then to examine the heuristic performance of the second critical point of Robbins' text: the preeminence of the ritual as a locus for the understanding of the schemes of adherence to values and their complex interaction.

Robbins considers that the ritual experience effectively condenses the expression of part of the values in tension in society, producing a peculiar coherence: "it is in ritual, in contrast to daily life, that I want to argue that people come closest to realizing single values fully". His demonstration of this question through successful and unsuccessful examples among the Urapmin is quite convincing - but how does one find equivalents between that social dynamics and that of a complex national society such as the Brazilian?

My guess is that one could draw inspiration from Robbins' proposal to find out the instances or spheres in which a homologous effect could occur here; and then it occurs to me that, more than the ritual in the strict sense (if one can recognize a strict sense for a category with a such 
controversial extension), a perception of intense or "dense situations" should be taken into account; at times religious rituals, but not necessarily so.

I think of the crises and dramas that befall people and collectivities in so many moments, those which Anglo-Saxon anthropology called "afflictions", and to which V. Turner dedicated an insightful analysis. It is there that these complex modern "therapeutic itineraries" are triggered, through various often disparate rituals, but also through these great collective movements, modern corroborees, in which accumulated anxieties are agglutinated among the theatric rites of Pentecostal temples and their giant replicas in outdoor concentrations. There are, however, many crises and dramas which may crystallize through the option for precise values entirely outside religion, or many others that can develop among the multiplicity of available rituals in a modern national market, seeking coherence at the plain experiential level, the least common multiple of a myriad of life tracks.

In the paper in which I more fully developed the issue of the two structuring values, I offered several examples of a search for articulation between subjectivism and naturalism, and between them and the underlying relatedness, through the account of many experiences - sometimes religious, sometimes medical, sometimes magical - that allowed for the final option regarding an artificial insemination, for a professional or a therapeutic choice, or for a marital or sexual decision. Dumont, who is so very fundamental for Robbins' analyses, might have suggested that his notion of "levels" or "situations" could encompass the proposal of the concentrated efficiency of rituals, but would also have broaden the scope to more complex situations, where the relevant difference is less that which draws from everyday life and ritual (clearer in small-scale societies) than another of greater or lesser levels and instances of intensity and embodiment. The decision between life alternatives as a critical challenge, experienced as personal drama, manifests itself in an intense experiential level different than that of everyday, pedestrian decisions; but also at a different level than that which prevails in the institutional religious, congregational or ritual sphere.

This observation does not question the basis of Robbins' hypothesis concerning the selective effect of rituals regarding values and its therefore increased efficiency; it only suggests that, in complex societies, the multiplicity of rituals enhances the differences of values, rather than solves it, therefore requiring other levels of production of active coherence.

It is important, however, to recognize that quite often the ritual experience may here as well present a precise force, drawing a dividing line between everyday multiplicity and the needed coherence of values. Robbins evokes the fundamental role of charismatic experience to actualize a 
certain presence of individualism, just as I suggested regarding subjectivism - but, as is well known, this radical experience of the self in the strengthening of the relationship with one's own body and mind tends to materialize in a congregational setting, where individualization or subjective autonomy is confronted with both a strict extramundane and intra-mundane relational order, in a very similar way, indeed, to all experiences of possession in a religious context, as in traditional Brazilian Candomble.

The distinctness of these dividing lines in the case of Brazilian society is, however, encompassed by the fluidity of transits and passages alongside religious careers, much more frequent than clear cut and definitive paths. In such a scenario, it would be difficult to agree with Robbins suggestion that "boundary crossing and identity switching are no longer major issues". Even if one highlights the multiplicity of values at hand and one suggests - as I have myself done that the more structuring values may not be properly "religious", the condensation of values made effective by formal religions in complex societies is a key component of the cultural framework, even for those subjects who move away from or do not pay special attention to them. And the phenomenon of multiple passages in no way diminishes the centrality of identity options involved in each step of such trajectories. The experience of crossing boundaries and the switching of identities is an intrinsic characteristic of the profound, radical rupture we call conversion - an issue which is so directly addressed by Robbins in his critique of continuity readings within anthropology.

Robbins' anti-identity assertion emerges in the context of his proposal of a tension between the monist and pluralist attitudes regarding values. And even he himself comments how this classification scheme is relevant for the understanding of different religions, especially in the opposition among the various versions of Christianity (and even of Pentecostalism itself). His final question about the social conditions that favor these different attitudes in this or that historical context is of great relevance, and has been directly addressed by many experts studying the phenomenon of Brazilian Pentecostalism (and of other religious phenomena in the modern world, such as fundamentalism). A great perplexity has accompanied the evidence of monist alternatives emerging in a society such as the Brazilian, secularly characterized by pluralisms agglutinated around Christianity (in spite of the Catholic Church), Kardecism and traditional African-Brazilian religions.

But this monism became established especially due to a strong emphasis on identity boundaries, carefully guarded around the moral and behavioral "small differences", even more than 
the grand, conceptual and doctrinal ones. Moreover, it is considered that this insistence on unitary coherence was - and still is - the main asset of Pentecostal expansion, as opposed to traditional pluralism, associated with magic and the deceptive arts of the devil in the native imagination, on one hand, and with the looseness in the way of self-assertion in sociological interpretations, on the other. The emergence of more accommodating ways, such as the UCKG, only confirms that this point is crucial, and that the offer of an alternative mediation in certain aspects meets the role of fulfilling a rich gamut of variations. In this issue as a whole, we must distinguish the dynamics of institutions and the dynamics of membership. One can say that the former tend more directly to monism, in order to characterize a distinctive, formal, canonical corpus. On the other hand, the (current or potential) believers, except for the specialists or virtuosi, tend to live with pluralistic forms, exposed as they are to the "market" relativity I mentioned before, and to the complexity of the ethical demands imposed by real life, its crises, tragedies and afflictions.

The strength and extent of the multiplicity of contemporary monisms and pluralisms fits my proposal of the existence of large confrontations of values in constant interaction in modern societies, in the form of an instituting schismogenesis, mostly concerning the private ethos and its "controversial moral issues" (Duarte, 2009a; Duarte, 2009b). Only then, in my opinion, one could understand the concomitant and exponential expansion of liberal tendencies and the intensification of traditional moral conventions, especially in Pentecostal denominations (in casual alliances with the historic Protestant and Catholic churches, but also with some secular professional sectors). Subjectivist and individualistic values that lead, for example, to advocate for the right to abortion or euthanasia are symmetrically opposed to values which are, at the same time, relational and naturalist and report such practices as contrary to "life" and "family." The steps ahead in liberalizing customs trigger an entrenchment in defense of traditional relational formulas in a typically schismogenetic scale. The confrontation of values is experienced by everyone in their current lives, as crisis or drama, but it never fails to pass through institutional mediation, be it of churches, or of organized civil society institutions or movements. In all of this, there are important ritual episodes, religious or civil, of both personal and collective interest, where the exacerbated defense of this or that value is staged, but that tend to be dispersed in the aforementioned multiplicity of possible actions and their public reverberations through the press.

Though having somewhat rapidly dismissed the dimension of identity boundaries, which can be understood in the light of the ethnological origins of his proposal, Robbins' willingness to deal with values is a welcome breath of opposition to anti-holistic trends present in contemporary 
anthropology, obsessed with the denouncement of the attention given to totalities (society, culture etc.), or to the idea of coherence (in a wide range that goes from F. Barth and M. Strathern through all the post-social and poststructuralists). These empiricist and nominalist trends tend to shift all the importance of the analysis to individual practice and public performance, considering spurious the invocation of any second level category, collective or aggregated. The emphasis on values recovers, in my opinion, the best of the language paradigm that supported structuralism, and re-positions the analysis in the fulcrum of the symbolic order, of the network of meanings, the only place from where practical instances, social speech acts, can emerge. Robbins' emphasis on the centrality of ritual is less a trait of pragmatism and more a strategic location of the manifestation of structured and structuring values.

Anthropological comparison, whether that of small differences or that of radical oppositions, retains all its heuristic potential, nourished especially, as always, by the confrontation between societies of different scales, be it tribal, peasant or urban complex. This could not be otherwise, since the pool of questions that anthropology brings up is unique and comprehensive, resulting from questions and concerns raised by the experience of Western culture itself, which invented this paradoxical knowledge and commanded the understanding of otherness with which we are concerned. The values in opposition in Western culture, whose refractions upon anthropology I have modeled in the summary form of an opposition between Enlightenment and Romanticism (in its notorious correlation with the opposition between individualism and holism, as suggested by Dumont), entail powerful contradictions in their theoretical formulation and tenacious challenges in their practical fulfillment. In another text, Robbins proposed that the incomplete, open nature of the individualistic setting (deriving from the Enlightenment, one might also say), in its continuous tension with holism, ensures the emergence of combinations of a particularly dynamic and resourceful nature, enabling greater multiplicities than those that most likely permeate all cultures . Just as the tension between the values of politeness and honesty was useful for Robbins to illustrate the dynamics of modern Western academic life - a process which a debate such as this, stemming from his text, stages one more time - many tensions among other academic values will be confronted here (epistemological models, methodological emphases, principles of analysis etc.). The ritual of a multivocal debate published in a scientific journal may be a good test of the author's proposal regarding the crucial nature of this dimension of the social experience of values.

\section{References:}

Debates do NER, Porto Alegre, ANO 15, N. 26, JUL/DEZ.2014. 
Birman, Patricia. Cultos de possessão e pentecostalismo no Brasil: passagens. Religião e Sociedade, n.17, v.1, p.90-109, 1996.

Duarte, Luiz Fernando Dias. Da Vida Nervosa (nas classes trabalhadoras urbanas). Rio de Janeiro: Jorge Zahar, Editor/CNPq, 1986.

. Ethos privado e racionalização religiosa. Negociações da reprodução na sociedade brasileira. In: Heilborn, M. L. ; Duarte, Luiz.; Lins de Barros, M.; Peixoto, C. Relações Familiares, Sexualidade e Religião. Rio de Janeiro: Garamond, 2005.

. Família, Moralidade e Religião: tensões contrastivas contemporâneas à busca de um modelo. In: Velho, Gilberto; Duarte, Luiz Fernando Dias. Gerações, família, sexualidade. Rio de Janeiro: Editora Sete Letras, 2009a.

Duarte, Luiz Fernando Dias; Jabor, Juliana; Gomes, Edlaine C.; Luna, Naara. 2006. Família, Reprodução e Ethos Religioso - subjetivismo e naturalismo como valores estruturantes. In: Duarte, L. F. D.; Heilborn, M. L.; Lins de Barros, M.; Peixoto, C. Família e Religião. Rio de Janeiro: Contra Capa, 2006.

Duarte, Luiz Fernando Dias; Gomes, Edlaine de C.; Menezes, Rachel A.; Natividade, Marcelo . 2009b. Valores Religiosos e Legislação no Brasil. A tramitação de projetos de lei sobre temas morais controversos. Rio de Janeiro: Editora Garamond, 2009b.

Duarte, Luiz Fernando Dias; Edlaine de C. Gomes. Três Famílias: identidades e trajetórias transgeracionais nas classes populares. Rio de Janeiro, Editora FGV, 2008.

Dumont, Louis. Homo Aqualis: génèse et épanouissement de l'idéologie économique. Paris, Gallimard, 1977.

Dumont, Louis. O individualismo: uma perspectiva antropológica da ideologia moderna. Rio de Janeiro: Rocco, 2000.

Pouillon, Jean. Remarques sur le verbe croire. In: Izard, Michel; Smith, Pierre. La fonction symbolique.Paris: Gallimard, 1979.

Robbins, Joel. On the Paradoxes of Global Pentecostalism and the Perils of Continuity Thinking. Religion, v. 33, n. 3, p. 221-31, 2003.

Robbins, Joel. Becoming Sinners. Christianity and Moral Torment in a Papua New Guinea Society. Berkeley. Los Angeles. London, University Of California Press, 2004.

Robbins, Joel. Continuity Thinking and the Problem of Christian Culture, Current Anthropology, v. 48 , n. 1 , p. $5-38,2007$. 
Robbins, Joel. Relationships as a Value: On Dumont and Relationalism in Melanesia. Paper presented at a session "Dumond in the Pacific" in annual meetings of ASAO. Santa Cruz, CA, 2009.

Salem, Tania. Tensões entre gêneros nas classes populares: uma discussão com o paradigma holista. Mana. Estudos da Antropologia Social. n.12, v.2, p.419-447, 2006.

Xavier, Carlos. Os Koripako do Alto Içana. Etnografia de um grupo indígena evangélico. Tese de Doutorado, Programa de Pós-Graduação em Antropologia Social, Museu Nacional, UFRJ, 2013.

Trad. Pietra Acunha (acadêmica do Bacharelado em Letras da UFRGS)

Revisão Prof. Rosalia Garcia (professora associada UFRGS) 
